\title{
Regular Graphs and Corona Graphs Based on Special Type of Labeling
}

\author{
Shalini Rajendra Babu, N. Ramya
}

\begin{abstract}
Here we consider the special type of labeling as lucky edge labeling for Regular graphs and corona graphs.
\end{abstract}

Keywords: Corona graph, Lucky edge labeling, Regular graph.

\section{INTRODUCTION}

A Let $\mathrm{G}$ be a graph as follows,

(i) $G$ is non-empty (ii) $G$ is finite

(iii) edges and $\eta(G)$ is maximum labels has been given in the graph.

If $\mathrm{G}$ is said to be regular graphs, each vertex have same neighbors.

Corona graph is obtained from two graphs, $\mathrm{G}$ of order $\mathrm{P}$ and $\mathrm{H}$, taking one copy of $\mathrm{G}$ and $\mathrm{P}$ copies of $\mathrm{H}$ and joining by an edge the $i^{\text {th }}$ vertex of $\mathrm{G}$ to every vertex in the $i^{\text {th }}$ copy of $H$.

\section{MAIN RESULTS.}

\section{A. Theorem 3.1}

For every $n \geq 4$ where $n$ is an even number, there exists a 3-regular $\left(n_{v} \frac{m}{2}\right)$ graph which holds Lucky edge labeling. [4]

Proof:

To prove that for 3-regular graph which admits Lucky edge labeling with lucky number is $4 i+3$ where $i=1,2,3 \ldots$ respectively.

Define the vertex labeling, for all $n \geq 4$ (where $n$ is an even number)

Revised Manuscript Received on December 30, 2019.

* Correspondence Author

Shalini Rajendra Babu*, BIHER, Chennai (Tamil Nadu) India.

E-mail: rshalini19@hotmail.com

Dr. N. Ramya, professor, BIHER, Chennai (Tamil Nadu) India. E-mail: drramyamaths@gmail.com

(C) The Authors. Published by Blue Eyes Intelligence Engineering and Sciences Publication (BEIESP). This is an open access article under the CC BY-NC-ND license (http://creativecommons.org/licenses/by-nc-nd/4.0/)

$$
\begin{aligned}
& f\left(v_{i}\right)=i \text { for all } i \\
& \text { Let } f: E \rightarrow\left\{1,2,3, \ldots \frac{3 n}{2}\right\} \\
& f\left(v_{i}, v_{i+1}\right)=2 j-1, \text { when }\left\{\begin{array}{l}
i=1,2,3, \ldots \\
j=2,3,4, \ldots
\end{array}\right. \text { respectively } \\
& f\left(v_{n}, v_{1}\right)=n+1 \text { when } n=4,6,8 \text {,.. } \\
& f\left(v_{1}, v_{n-k}\right)=n-k+1 \text {, when } k=1,2,3, \ldots \\
& \mathrm{f}\left(\mathrm{v}_{2+\mathrm{i}}, \mathrm{v}_{4+\mathrm{j}}\right)=6+\mathrm{i}+\mathrm{jwhenn}=4 \text {, fori }=0, \mathrm{j} \\
& =0 \text { then edges of the form. } \\
& f\left(v_{2+i}, v_{4+j}=6+i+j \text { when } n=6 \text {, for }(i=0, j\right. \\
& =1) \text { and }(i=0, j=1) \text { and }(i=1, j \\
& =2 \text { ) then the edges of the form } \\
& f\left(v_{2+i}, v_{4+j}\right)=6+i+j \text { when } n=8 \text {, for }(i=0, j \\
& =2),(i=1, j=3) \text { and }(i=2, j \\
& =4) \text { then edges of the form }
\end{aligned}
$$

The number of crossing edges, barring those crossing edges incident with $\mathrm{v}_{1}$ are 1,2,3,4 respectively, that edges must be labeled as of the form

Similarly, $\mathrm{n}=10,12,14, \ldots$

\begin{tabular}{|c|c|c|}
\hline $\mathbf{n}$ & $\mathbf{i}$ & $\mathbf{j}$ \\
\hline 4 & 0 & 0 \\
\hline 6 & $(0,1)$ & $(1,2)$ \\
\hline 8 & $(0,1,2)$ & $(2,3,4)$ \\
\hline 10 & $(0,1,2,3)$ & $(3,4,5,6)$ \\
\hline 12 & $(0,1,2,3,4)$ & $(4,5,6,7)$ \\
\hline
\end{tabular}

Illustration: $\mathrm{n}=4$

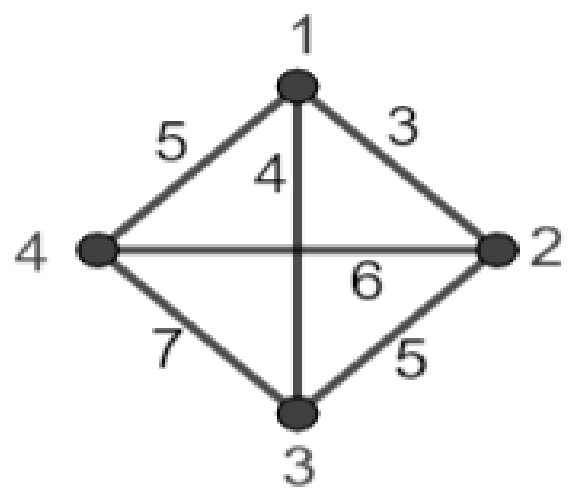

Hence, a 3- regular $(4,6)$ graph which admits Lucky edge labeling and its lucky number is 7 .

Illustration: $\mathrm{n}=10$

Hence, a 3- regular $(4,6)$ graph which admits Lucky edge labeling and its lucky number is 7 . 


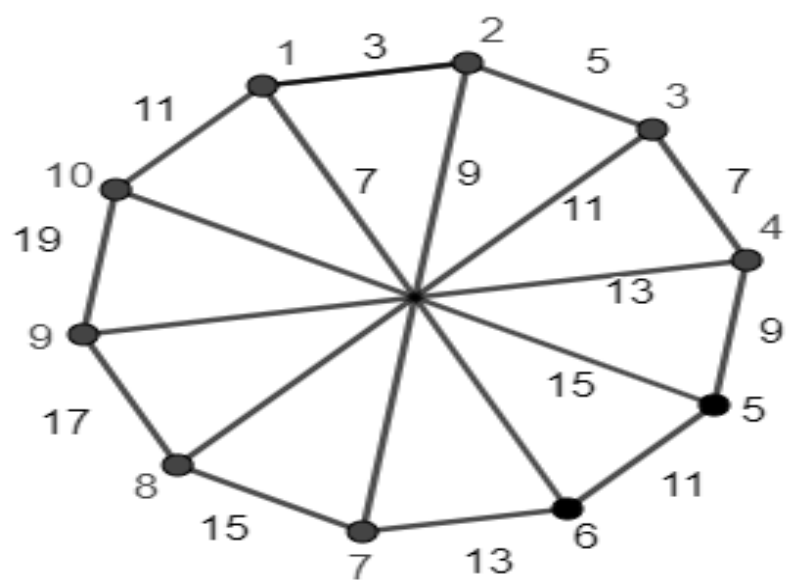

Hence, a 3- regular $(10,15)$ graph which admits Lucky edge labeling and its lucky number is 19 .

\section{B. Theorem 3.2}

For every $n \geq 5$ there exists a 4 - regular (n, 2n) graph which admits Lucky edge labeling. [4].

\section{Proof:}

To prove that for 4-regular $(n, 2 n)$ graph [4] its lucky number is $2 \mathrm{n}-1$.

Define the vertex labeling for all $n \geq 5$.

$\mathrm{f}\left(\mathrm{v}_{\mathrm{i}}\right)=\mathrm{i}$ for all $\mathrm{i}$

Let $\mathrm{f}: \mathrm{E} \rightarrow\{1,2,3, \ldots 2 \mathrm{n}\}$ such that

$$
\begin{gathered}
f\left(v_{1}, v_{n}\right)=n+1 \\
f\left(v_{i}, v_{i+1}\right)=2 i+1, \text { where } i=1,2,3, \ldots .
\end{gathered}
$$

These all are the external edges; rest of the edges are crossing edges. It can be associated as,

$$
\begin{gathered}
f\left(v_{1}, v_{n-1}\right)=n \\
f\left(v_{2}, v_{n}\right)=n+2 \\
f\left(v_{i}, v_{i+2}\right)=2 i+2, \text { where } i=1,2,3, \ldots
\end{gathered}
$$

\section{Illustration: When $\mathrm{n}=5$}

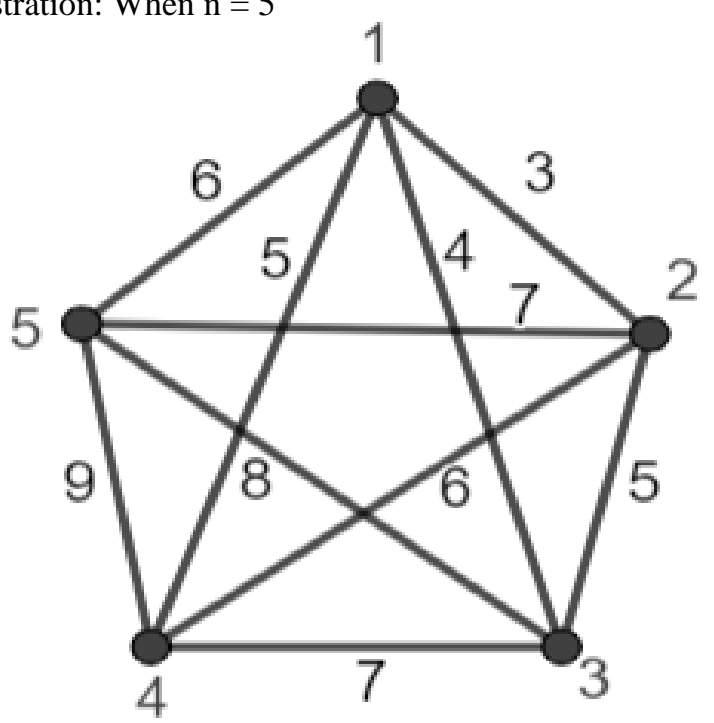

Hence, a 4- regular $(5,10)$ graph which admits Lucky edge labeling and its lucky number is 9 . Illustration: When $\mathrm{n}=7$

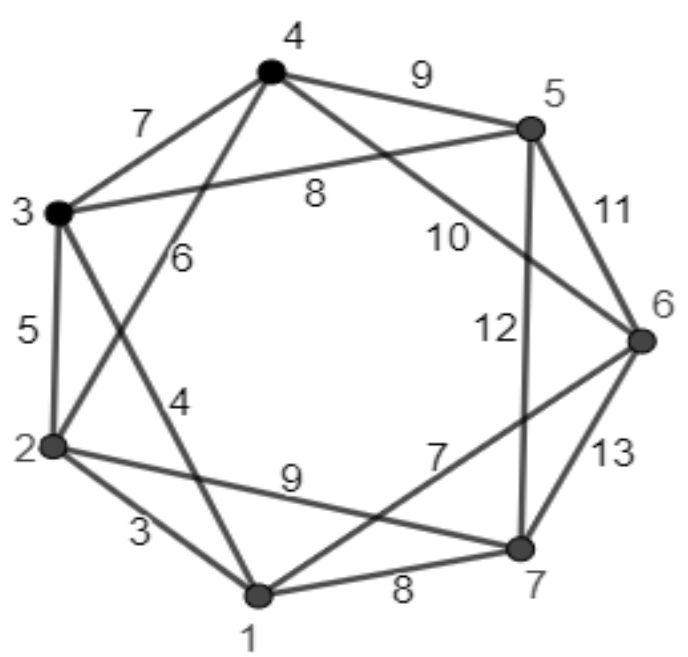

Hence, a 4- regular $(7,14)$ graph which admits Lucky edge labeling and its lucky number is 13 .

\section{Theorem 3.3}

The corona graph $P_{\mathrm{n}} \odot K_{2}$ always contains a lucky edge labeling.

\section{Proof:}

In $G=P_{n} \odot K_{2}$, construction of vertex set, and edge as follows.

Let $v(G)=v\left(P_{n}\right) \cup v\left(n k_{2}\right)$

Where $v\left(P_{n}\right)=\left\{u_{v} u_{2, x}, u_{n-1}, u_{n}\right\}$ and

$$
v\left(n K_{2}\right)=\left\{v_{1}, v_{2}, \ldots v_{2 n-1}, v_{2 n}\right\} \text {. }
$$

$E(G)=\left\{u_{i}, u_{I+1} ; 1 \leq i \leq n-1\right\} \cup\left\{v_{2 i-1} v_{n}, 1 \leq i \leq\right.$

$n\} \cup\left\{u_{i,}, 1 \leq i \leq n\right\} \cup\left\{u_{i} v_{2 i}, 1 \leq i \leq n\right\}$

be the vertex set and edge set of $G$ respectively. [6]

Now $|v(G)|=3 n$ and $|E(G)|=4 n-1$.

We will classify the edges of corona of $P_{n} \odot K_{2}$ in three cases.

i)Path edges

ii) $K_{2}$ edges

iii)Edges joining from $K_{2}$ with the path.

Vertex set defined as,

$$
\begin{gathered}
f\left(u_{i}\right)=1 \\
f\left(u_{i+1}\right)=4 \text {, when } i=2,3,6,7, \ldots \\
f\left(v_{i}\right)=2 \text {, when } i=1,2,3,4, \ldots \\
f\left(w_{i}\right)=3 \text {, when } i=1,2,3,4, \ldots \\
\text { Edge Set defined as, } \\
f\left(u_{i} u_{i+1}\right)=2, \text { when } i=1,5,9, \ldots \\
f\left(u_{i}, u_{i+1}\right)=5 \text {, when } i \text { is an even } \\
f\left(u_{i}, u_{i+1}\right)=8 \text {, when } i=3,7,11, \ldots \\
f\left(u_{i}, v_{i}\right)=3 \text {, when } i=1,2,5,6,9,10, \ldots \\
f\left(w_{i}, u_{i}\right)=4, \text { when } i=1,2,5,6,9,10, \ldots \\
f\left(u_{i}, v_{i}\right)=6, \text { when } i=3,4,7,8, \ldots \\
f\left(v_{i}, w_{i}\right)=5 \text {, when } i=3,4,7,8, \ldots \\
f\left(w_{i}, u_{i}\right)=7, \text { when } i=3,4,7,8, \ldots
\end{gathered}
$$




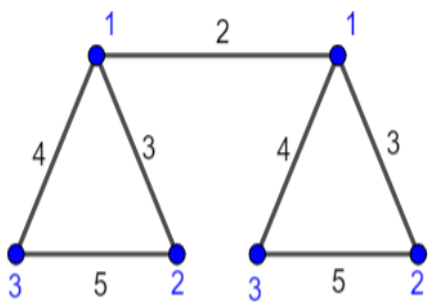

The Lucky number of $P_{2} \odot K_{2}$ is 5 .

Illustration: $P_{4} \odot K_{2}$

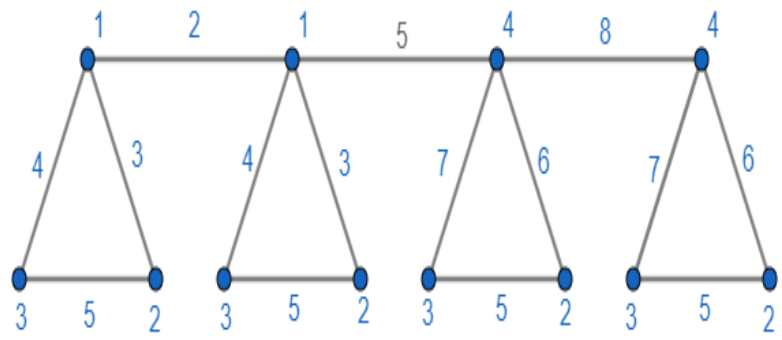

The Lucky number of $P_{4} \odot K_{2}$ is 8 .

\section{Theorem 3.4}

The corona graph $P_{n} \odot C_{4}$ always admits a lucky edge labeling.

\section{Proof:}

In a graph $G=P_{n} \odot C_{4}$, construction of $\mathrm{V}(\mathrm{G})$ and $\mathrm{E}(\mathrm{G})$ as follows,

Let $v(G)=v\left(P_{n}\right) \cup\left(C_{4}{ }^{1}\right) \cup v\left(C_{4}{ }^{2}\right) \cup \ldots \cup v\left(C_{4}{ }^{n}\right)$

where $v\left(P_{n}\right)=\left\{u_{1}, u_{2}, u_{n}\right\}$ and $v\left(C_{4}{ }^{i}\right)=$

$\left\{v_{i}, w_{i}, x_{i}, y_{i}: 1 \leq i \leq n\right\}$

and $C_{4}{ }^{i}$ is the $i^{\text {th }}$ copy of $C_{4}$ be the vertex set and edge set of $G$ respectively. [6]

The corona of $P_{4} \odot C_{4}$ is given below.

$|v(G)|=5 n$ and $|E(G)|=9 n-1$.

Vertex set can be defined as follows

$$
\begin{gathered}
f\left(u_{i}\right)=1, \text { when } i=1,2,5,6, \ldots \\
f\left(u_{i}\right)=6, \text { when } i=3,4,7,8 \ldots \\
f\left(v_{i}\right)=2, \text { when } i=1,2,3,4, \ldots \\
f\left(w_{i}\right)=3, \text { when } i=1,2,3,4, . . \\
f(x)=4, \text { when } i=1,2,3,4, \ldots \\
f\left(y_{i}\right)=5 \text {, when } i=1,2,3,4, \ldots
\end{gathered}
$$

Edge Set can be defined as

$$
\begin{aligned}
& f\left(u_{i}, u_{i+1}\right)=2 \text {, when } i=1,5,9, \ldots \\
& f\left(u_{i}, u_{i+1}\right)=7 \text {, when } i \text { is an even } \\
& f\left(u_{i}, u_{i+1}\right)=12 \text {, when } i=3,7,11, \ldots \\
& f\left(v_{i}, w_{i}\right)=5 \text {, when } i=1,2,3, \ldots \\
& f\left(v_{i}, y_{i}\right)=7 \text {, when } i=1,2,3, \ldots \\
& f\left(u_{i}, y_{i}\right)=6 \text {, when } i=1,2,5,6, \ldots \\
& f\left(u_{i}, y_{i}\right)=11 \text {, when } i=3,4,7,8, \ldots \\
& f\left(u_{i}, x_{i}\right)=5 \text {, when } i=1,2,5,6, \ldots \\
& f\left(u_{i}, x_{i}\right)=10 \text {, when } i=3,4,7,8, \ldots \\
& f\left(x_{i}, y_{i}\right)=9 \text {, when } i=1,2,3,4, \ldots \\
& f\left(w_{i}, x_{i}\right)=7 \text {, when } i=1,2,3,4, \ldots \\
& f\left(u_{i}, w_{i}\right)=4 \text {, when } i=1,2,5,6 \ldots \\
& f\left(u_{i}, w_{i}\right)=9 \text {, when } i=3,4,7,8, \ldots \\
& f\left(u_{i}, v_{i}\right)=3 \text {, when } i=1,2,5,6 \text {... } \\
& f\left(u_{i}, v_{i}\right)=8 \text {, when } i=3,4,7,8 \text {... }
\end{aligned}
$$

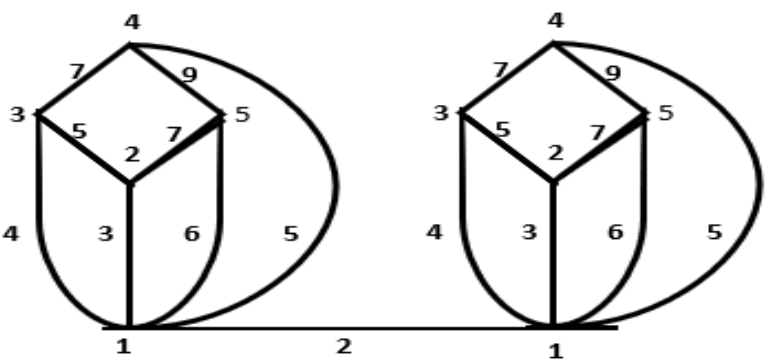

The Lucky number of $P_{2} \odot C_{4}$ is 9 .

Illustration: $P_{4} \odot C_{4}$

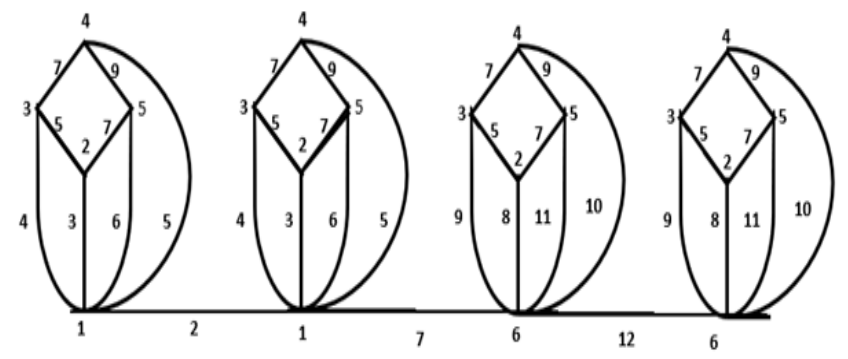

The Lucky number of $P_{4} \odot C_{4}$ is 12 .

\section{CONCLUSION}

Here we establish the fact the Lucky edge labeling based on special type of graphs that is $P_{n} \odot C_{4}, P_{n} \odot K_{2}$, 3-regular and 4-regular graphs. This can be extended for generalized Corona and Regular graphs.

\section{REFERENCES}

1. Dr. Nellai Murugan.A, Maria Irudhaya Aspin Chitra.R "Lucky Edge labeling of Pn, Cn and Corona of Pn, Cn” IJSIMR PP: 710-718, 2014

2. Dr. Nellai Murugan.A, Maria Irudhaya Aspin Chitra.R "Lucky Edge labeling of Triangular Graphs" IJMTT-Vol.36(2)-2016.

3. Gallian J.A. "A dynamic survey of graph labeling”. The electronic Journal of Combinatorics, (2012) \#DS6.

4. Ramya. N, Rangarajan, Sattanathan.R "On vertex bimagic and Antimagic Labeling of regular graphs". Proceedings of ICMEB 2012,103-105.

5. Kaladevi.V and Kavitha.G "Edge-odd graceful labeling of some corona graphs”. Proceedings of ICMEB2012, PP 77-79.

\section{AUTHORS PROFILE}

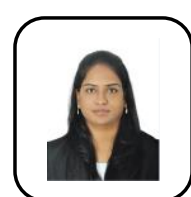

Mrs. Shalini Rajendra Babu, Pursuing Ph.D. in the area of Graph theory at BIHER, Chennai. She has presented papers in Conferences and published papers.

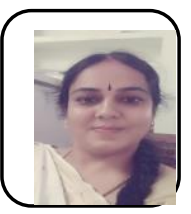

Dr. N. Ramya, obtained Ph.D. In the field of Graph theory. She published 15 papers in National as well international journals. She is working as a professor at BIHER Chennai.

Illustration: $P_{2} \odot C_{4}$ 